\title{
Predictability of sustainable investments and the role of uncertainty: Evidence from a non-parametric causality-in-quantiles test
}

\author{
Nikolaos Antonakakis*, Vassilios Babalos** and Clement Kyei ${ }^{* * *}$
}

\begin{abstract}
In this paper we examine sustainable investments returns predictability based on the US Dow Jones Sustainability Index (DJSI) and a wide set of uncertainty and financial distress indicators for the period January 2002 to December 2014. To this end, we employ a novel nonparametric causality-in-quantile approach that captures non-linearities in returns distribution. Based on our findings we conclude that the aggregate Economic Policy Uncertainty (EPU) indicator and some components have predictive ability for real returns of the US sustainable investments index. Moreover, if we split our sample to before and after the global financial crisis our results suggest that predictors carry causal information for real returns only in the after crisis period. Finally, some marginal evidence of predictability from Sovereign Debt is also observed at the lower and upper-ends of the conditional distribution of the real returns of sustainable investments. Our results might entail policy implications for investors and market authorities.
\end{abstract}

Keywords: sustainable investments, predictability, economic policy uncertainty, non parametric quantile causality

JEL Classification: C32, G11

\footnotetext{
* Corresponding author. Economics \& Finance Subject Group, University of Portsmouth, PO1 3DE, Portsmouth, UK. Email: nikolaos.antonakakis@port.ac.uk; Department of Business \& Management, Webster Vienna Private University, 1020, Vienna, Austria. Email: nikolaos.antonakakis@webster.ac.at.

** Department of Accounting \& Finance, Technological Educational Institute of Peloponnese; Department of Banking \& Financial Management, University of Piraeus, Greece. Email: vbabalos@teikal.gr.

*** Department of Economics, University of Pretoria, Pretoria, 0002, South Africa. Email: rangan.gupta@up.ac.za.
} 


\section{Introduction}

Sustainable or socially responsible investments have long been recognized as a noteworthy investment vehicle for retail and institutional investors. Sustainable investments is a broad investment strategy that encompasses environmental, social, governance screens into the investment selection process (Ghoul and Karam, 2007; Renneboog et al., 2008). The history of sustainable investments goes back to 1758 where the Quaker Philadelphia strictly forbidden their member from taking part in slave and weapon trading (Renneboog et al., 2008). Moskowitz (1972) was the first that introduced methods of selecting stocks complying with socially responsible norms. Most studies on the area of sustainable investments examine whether there are performance differences between sustainable and conventional portfolios reaching contradictory results (for a review of the relevant studies see Lean and Nguyen, 2014). However, none of the studies so far has examined the predictability of sustainable investments.

The literature on forecasting stock market returns is voluminous. A strand of that focuses on the predictive ability of financial and macroeconomic variables across different time horizons both in developed (e.g. Campbell, 1987; Breen et al., 1990; Pesaran and Timmermann, 1994, 1995 for US markets and Clare et al., 1994; Fama and French, 1998; Pesaran and Timmermann, 2000, for some other markets) and emerging markets (Lewellen, 2004; Guo, 2006). More recently, Chava et al. (2015) confirmed an inverse relationship between credit conditions and stock market returns in USA. In addition, an interesting grouping of relevant studies classifies studies into cross-sectional and time series studies. Cross-sectional studies of US equity returns have revealed that stocks' fundamental variables, such as earnings yield, cash flow yield, book-to-market ratio and size, have predictive power (e.g. Basu, 1977; Fama and French, 1992; Lakonishok, Shliefer and Vishny, 1994). In time series analysis Fama and French (1993) report three common risk factors, namely, market risk, size and book-tomarket, which are able to explain average stock returns.

Another strand of literature reports predictive power in a variety of other variables, including interest rates, inflation and output (e.g. Keim and Stambaugh, 1986; Campbell, 1987; French, Schwert and Stambaugh, 1987; Fama and French, 1989, Balvers, Cosimano and McDonald, 1990; Breen, Glosten and Jagannathan, 1990; Cochrane, 1991; Campbell and Hamao, 1992; Ferson and Harvey, 1993; Glosten, Jagannathan and Runkle, 1993). 
Thus, our study is motivated by the aforementioned gap in the literature. In addition, our study is also motivated by several papers that study the impact of policy uncertainty on conventional stock market returns. For example, Pastor and Veronesi (2012) in a theoretical analysis proved that US policy changes induce volatility, risk premia, and correlations among stocks. Moreover, Kanga and Ratti (2013) reported that a shock in policy uncertainty has a significant negative effect on US real stock returns.

Therefore, in view of the growing popularity of sustainable investments, the purpose of the present study is to fill the gap in the literature that deals with sustainable investments returns predictability. To the best of our knowledge, this is the first study that attempts to shed light on the sustainable investments returns predictability based on a series of market-wide uncertainty indicators and financial distress.

Thus, this paper's contributions to the literature are as follows. On methodological grounds, we propose to employ a nonparametric quantile-in-causality approach of Jeong et al., (2012), which is justified by the strong non-linearities that characterize the employed series and the existing literature. For instance, the literature suggests that financial markets are characterised by bulls and bears (see, e.g. Epps, 1975; Day and Huang, 1990), and that bad news affect stock markets more than goods news (see, e.g., Campbell and Hentschel, 1992; Koutmos and Booth, 1995; Veronesi, 1999); thus giving rise to non-linearities. Moreover, the literature indicates that the effects of economic policy uncertainty on financial markets also exhibit nonlinearities (see, e.g., Bomfim, 2003, Chen 2007; Li, 2015; Chu, 2015). As such, the presence of potential non-linearities in our series is accounted for under our proposed methodology.

Second, we examine the predictability of sustainable investments using a broad set of uncertainty and financial distress indicators. The motivation for the examination of a broad set of uncertainty indicators, such as monetary policy, fiscal policy, health policy and national security policy uncertainty, among others, is to investigate whether the exist distinct patterns in the predictability of sustainable investments following changes in uncertainties of different aspects of the economy. For instance, monetary policy which was has reached its lower bound might translate to lower monetary policy uncertainty, while fiscal policy which has been currently on the frontline would translate to higher fiscal policy uncertainty. A similar argument can be raised for the other types of uncertainties. 
Third, the role of the global financial crisis in the causal relation between sustainable returns and uncertainty is also identified. Following the previous discussion, given that (e.g. fiscal) policy uncertainty was higher since the global financial crisis compared to that in the preglobal financial crisis, it would be of interest to examine whether the predictability of sustainable investments based on economic policy uncertainty differs during periods of high compared to low policy uncertainty.

Previewing our results, we document substantial evidence of nonlinearity in all the relationships between the real returns of the US DJSI and the various measures of uncertainty and that of the financial stress. Overall, during the period of analysis a set of seven predictors, namely, Entitlement Program, EPU, Fiscal Policy, Government Spending, Health Care, News-based version of the EPU, and Taxes carry predictive ability for the real returns of the US DJSI. Taking the analysis one step further the sample was divided into two subsamples in order to disentangle any possible effect of the global financial crisis on the hypothesized relation between the series. Interestingly, there was no sign of causality from any of the predictors during the pre-crisis period. Still, for the post-crisis period, besides, the seven variables which had predictability for the full-sample, two more predictors made their appearance, namely, CPI Disagreement and National Security.

The rest of the paper is structured as follows: Section 2 provides a description of the dataset and methodology employed. Section 3 presents the empirical results and finally, Section 6 summarizes the main empirical findings and concludes the paper.

\section{Data and Methodology}

The data used in this study includes a measure of real returns on the US Dow Jones Sustainable Index (DJSI hereafter), and various, EPUs, measures of debt-ceiling, government shutdown, and financial stress, at a monthly frequency covering period of 2002:01-2014:12. The US DJSI is obtained from Datastream of Thomson Reuters at daily frequency, and then converted to monthly frequency, to match the frequency of our predictors, by averaging over the days of the months. The real value of the index is then computed by deflating the nominal index with the US Consumer price Index (CPI). Then real returns (in percentages) are computed by taking the first differences of the natural logarithms of the real index multiplied 
by 100 . Hence, we miss the observation for the month of January of 2002. Note that, working with real returns also ensures that our dependent variable is stationary. ${ }^{1}$

While the start date of the sample is determined by the availability of data on the DJSI, the end-point is governed by data on our predictors. We work with natural logarithms of our predictors, which is enough to ensure stationarity of these variables. ${ }^{2}$ The predictors used are primarily the aggregate EPU, developed by Baker et al., (2013), and the three types of underlying components used to construct the EPU: newspaper coverage of policy-related economic uncertainty (News_Based_Policy_Uncert_Index) ${ }^{3}$; the number of federal tax code provisions set to expire in future years (Tax_expiration) ${ }^{4}$, and disagreement among economic forecasters (FedStateLocal_Ex_disagreement and CPI_disagreement) ${ }^{5}$. The monthly data, which starts in 1985:01 is available freely for download from: http://www.policyuncertainty.com/us_monthly.html. Then, the categorical EPU data includes a range of sub-indexes based solely on news data, and is available for download freely from: http://www.policyuncertainty.com/categorical_epu.html. These are derived using results from the Access World News database of over 2,000 US newspapers. Each sub-index requires our economic, uncertainty, and policy terms as well as a set of categorical policy terms: Monetary policy, Fiscal Policy and Government spending, Health care, National security, Entitlement programs, Regulation, Financial Regulation, Trade policy, Sovereign debt, currency crises. Further details are available at: http://www.policyuncertainty.com/categorical_terms.html. This data starts in 1985:01 as well. Besides this, data on the number of mentions of "government shutdown" or "debt ceiling" in newspapers across the United States since

\footnotetext{
${ }^{1}$ Complete details of the unit root tests are available upon request from the authors.

${ }^{2}$ Theoretically, measures of uncertainty should be stationary. However, statistically, it could deviate from this due to the sample period considered. But, the unit root tests revealed that the natural logarithm of the uncertainty-based predictors did not contain unit roots, and hence, could be used in levels in our analysis. Complete details of the unit root tests are available upon request from the authors.

${ }^{3}$ The first component is an index of search results from 10 large newspapers (USA Today, the Miami Herald, the Chicago Tribune, the Washington Post, the Los Angeles Times, the Boston Globe, the San Francisco Chronicle, the Dallas Morning News, the Houston Chronicle, and the Wall Street Journal). To construct the index, month-by-month searches of each paper is performed for terms related to economic and policy uncertainty. In particular, articles are searched for terms containing 'uncertainty' or 'uncertain', the terms 'economic' or 'economy' and one or more of the following terms: 'congress', 'legislation', 'white house', 'regulation', 'federal reserve', or 'deficit'. In other words, to meet the criteria for inclusion, the article must include terms in all three categories pertaining to uncertainty, the economy and policy.

${ }^{4}$ The second component draws on reports by the Congressional Budget Office (CBO) that compile lists of temporary federal tax code provisions. Temporary tax measures are a source of uncertainty for businesses and households, given that Congress often extends them at the last minute, and in the process, undermines stability in and certainty about the tax code.

${ }^{5}$ The third component draws on the Federal Reserve Bank of Philadelphia's Survey of Professional Forecasters. This quarterly survey covers a wide range of macroeconomic variables, with the index utilizing the individuallevel data for three of the forecast variables, the consumer price index (CPI), purchase of goods and services by state and local governments, and purchases of goods and services by the federal government.
} 
1985:01 until 2013:09, is used by Baker et al., (2013) to develop an index on government shutdown and debt ceiling. Finally, a measure of financial stress from the Kansas City Federal Reserve, i.e., the Kansas City Financial Stress Index (KCFSI), is also used. So, in total, we have one measure of financial stress and eighteen measures of various types of uncertainty, both aggregate and components. Barring the two indexes on government shutdown and debt ceiling, the data on all the other predictors ends in 2014:12. The evolution of these series is presented in Figure 1.

\section{[INSERT FIGURE 1 HERE]}

We study the predictability of various EPUs, measures of debt-ceiling, government shutdown, and financial stress by turn on the real returns of the DJSI of the US, using the method of nonlinear causality proposed by Jeong et al. (2012). ${ }^{6}$ We denote real stock returns as $\left(y_{t}\right)$ and the various predictors as $\left(x_{t, n}\right)$, where $n=1,2, \ldots, 19$.

Following Jeong et al. (2012), the quantile-based causality is defined as follows: ${ }^{7}$

$x_{t, n}$ does not cause $y_{t}$ in the $\theta$-quantile with respect to the lag-vector of $\left\{y_{t-1, n}, \ldots, y_{t-p, n}, x_{t-1, n}, \ldots, x_{t-p, n}\right\}$ if

$$
Q_{\theta}\left\{y_{t} \mid y_{t-1}, \ldots, y_{t-p}, x_{t-1}, \ldots, x_{t-p}\right\}=Q_{\theta}\left\{y_{t} \mid y_{t-1}, \ldots, y_{t-p}\right\}
$$

$x_{t, n}$ is a prima facie cause of $y_{t}$ in the $\theta$ th quantile with respect to $\left\{y_{t-1}, \ldots, y_{t-p}, x_{t-1}, \ldots, x_{t-p}\right\}$ if

$$
Q_{\theta}\left\{y_{t} \mid y_{t-1}, \ldots, y_{t-p}, x_{t-1}, \ldots, x_{t-p}\right\} \neq Q_{\theta}\left\{y_{t} \mid y_{t-1}, \ldots, y_{t-p}\right\}
$$

where $Q_{\theta}\left\{y_{t} \mid \cdot\right\}$ is the $\theta$ th quantile of $y_{t}$ depending on $t$ and $0<\theta<1$.

Let $Y_{t-1} \equiv\left(y_{t-1}, \ldots, y_{t-p}\right), Z_{t-1} \equiv\left(y_{t-1}, \ldots, y_{t-p}, x_{t-1}, \ldots, x_{t-p}\right), V_{t}=\left(Y_{t}, Z_{t}\right)$ and $F_{y_{t} Z_{t-1}}\left(y_{t}, Z_{t-1}\right)$ and $F_{y_{t} \mid Y_{t-1}}\left(y_{t}, Y_{t-1}\right)$ denote the conditional distribution functions of $y_{t}$ given $Y_{t-1}$ and $Z_{t-1}$ respectively. The conditional distribution $F_{y_{t} \mid Z_{t-1}}\left(y_{t}, Z_{t-1}\right)$ is assumed to be absolutely continuous in $y_{t}$ for almost all $V_{t-1}$. If we denote $Q_{\theta}\left(Z_{t-1}\right) \equiv Q_{\theta}\left(y_{t} \mid Z_{t-1}\right)$ and

\footnotetext{
${ }^{6}$ The reason we are only interested in the causal effect of EPU to sustainability index and not the reverse, is that uncertainty is a much wider concept and to expect sustainability index to affect uncertainty is out of scope of this paper. Nevertheless, we have examined the reverse causality and the results point to the aforementioned point that sustainability affects policy uncertainty.

${ }^{7}$ The exposition in this section closely follows Jeong et al. (2012).
} 
$Q_{\theta}\left(Y_{t-1}\right) \equiv Q_{\theta}\left(y_{t} \mid Y_{t-1}\right)$, we have $F_{y_{t} \mid Z_{t-1}}\left\{Q_{\theta}\left(Z_{t-1}\right) \mid Z_{t-1}\right\}=\theta$ with probability one. Consequently, the hypotheses to be tested based on definitions (1) and (2) are:

$$
\begin{aligned}
& H_{0}=P\left\{F_{y_{t} \mid Z_{t-1}}\left\{Q_{\theta}\left(Y_{t-1}\right) \mid Z_{t-1}\right\}=\theta\right\}=1 \\
& H_{1}=P\left\{F_{y_{t} \mid Z_{t-1}}\left\{Q_{\theta}\left(Y_{t-1}\right) \mid Z_{t-1}\right\}=\theta\right\}<1
\end{aligned}
$$

Jeong et al. (2012) employs the distance measure $J=\left\{\varepsilon_{t} E\left(\varepsilon_{t} \mid Z_{t-1}\right) f_{z}\left(Z_{t-1}\right)\right\}$ where $\varepsilon_{t}$ is the regression error term and $f_{z}\left(Z_{t-1}\right)$ is the marginal density function of $Z_{t-1}$. The regression error $\varepsilon_{t}$ emerges based on the null in (3), which can only be true if and only if $E\left[1\left\{y_{t} \leq Q_{\theta}\left(Y_{t-1}\right) \mid Z_{t-1}\right\}\right]=\theta$ or equivalently1\{y $\left.y_{t} \leq Q_{\theta}\left(Y_{t-1}\right)\right\}=\theta+\varepsilon_{t}$, where $1\{\cdot\}$ is an indicator function. Jeong et al. (2012) specify the distance function as follows:

$$
J=E\left[\left\{F_{y_{t} Z_{t-1}}\left\{Q_{\theta}\left(Y_{t-1}\right) \mid Z_{t-1}\right\}-\theta\right\}^{2} f_{Z}\left(Z_{t-1}\right)\right]
$$

In Eq. (3), it is important to note that $J \geq 0$ i.e., the equality holds if and only if $H_{0}$ in (5) is true, while $J>0$ holds under the alternative $H_{1}$ in Eq. (4). Jeong et al. (2012) show that the feasible kernel-based test statistic for $J$ has the following form:

$$
\hat{J}_{T}=\frac{1}{T(1-1) h^{2 p}} \sum_{t=1}^{T} \sum_{s \neq t}^{T} K\left(\frac{Z_{t-1}-Z_{s}}{h}\right) \hat{\varepsilon}_{t} \hat{\varepsilon}_{s}
$$

where $K(\cdot)$ is the kernel function with bandwidth $h$ while $\hat{\varepsilon}_{t}$ is the estimate of the unknown regression error, which is estimated as follows:

$$
\hat{\varepsilon_{t}}=1\left\{y_{t} \leq Q_{\theta}\left(Y_{t-1}\right)-\theta\right\}
$$

$\hat{Q}_{\theta}\left(Y_{t-1}\right)$ is an estimate of the $\theta$ th conditional quantile of $y_{t}$ given $Y_{t-1}$. Below, we estimate $Q_{\theta}\left(Y_{t-1}\right)$ using the nonparametric kernel method as:

$$
\hat{Q_{\theta}}\left(Y_{t-1}\right)=\hat{F_{y_{t} \mid Y_{t-1}}^{-1}}\left(\theta \mid Y_{t-1}\right)
$$

where $\hat{F}_{y_{t} \mid Y_{t-1}}\left(y_{t} \mid Y_{t-1}\right)$ is the Nadarya-Watson kernel estimator given by: 


$$
\hat{F}_{\left.y_{i}\right|_{t-1}}\left(y_{t} \mid Y_{t-1}\right)=\frac{\sum_{s t t} L\left(\left(Y_{t-1}-Y\right) / h\right) 1\left(Y_{s} \leq Y_{t-1}\right)}{\sum_{s \neq t} L\left(\left(Y_{t-1}-Y\right) / h\right)}
$$

with $L(\cdot)$ denoting the kernel function and $h$ the bandwidth.

The empirical implementation of causality testing via quantiles entails specifying three important choices: the bandwidth $h$, the lag order $p$, and the kernel type for $K(\cdot)$ and $L(\cdot)$ in Eq. (6) and (9) respectively. In our study, the lag order of one is determined using the Schwarz Information Criterion (SIC) under an autoregressive (AR) model for real returns of the DJSI, as well as, VARs comprising of the real returns of the DJSI and the various predictors (EPUs, measures of debt-ceiling, government shutdown, and financial stress) by turn. ${ }^{8}$ Note that, using a lag-length of one makes our analysis consistent with the predictive regression-based studies on forecasting stock returns. The bandwidth value is selected using the least squares cross-validation method. Lastly, for $K(\cdot)$ and $L(\cdot)$ we employ Gaussian-type kernels.

\section{Empirical Results}

The distribution of the real returns on the US DJSI was found to be negatively skewed (1.3180), and have excess kurtosis (7.7705), yielding a Jarque-Bera statistics of 191.8536, whereby the null of normality was overwhelmingly rejected at 1 percent level of significance. This, in turn, is indicative of a heavy left-tail for the real returns on the US DJSI, and provides an initial motivation to look at the effect of the predictors over its entire distribution, rather than just in the conditional-mean. ${ }^{9}$

Next, to motivate the use of the nonparametric quantile-in-causality approach further, we investigate the possibility of nonlinearity in the real stock returns of the US DJSI on its own, and also in its relationship with the nineteen predictors. To do this, we apply the Brock et al., (1996, BDS) test on the residuals of an AR(1) model for real US DJSI returns, and the stock returns equation in the VAR(1) model involving the various predictors by turn. The BDS test, reported in Table 1, is found to reject the null of serial dependence at various dimensions,

\footnotetext{
${ }^{8}$ Complete details of the lag-length tests are available upon request from the authors.

${ }^{9}$ The Jarque-Bera test rejected the null of normality of the all the predictors 1 percent level of significance. Completed details of the summary statistics of the nineteen predictors are available upon request from the authors.
} 
mostly at the highest levels of significance, for the residuals of stock returns from the AR(1) model, and for the VAR(1) model involving the all the predictors, barring only the first dimension of Financial Regulation and Monetary Policy. In general, however, these results provide strong evidence of nonlinearity in the real stock returns, and its relationship with the predictors, which implies that we cannot base our inferences on a linear Granger causality test. $^{10}$

\section{[INSERT TABLE 1 HERE]}

Given the strong evidence of nonlinearity in all the relationships between the real returns of the US DJSI and the various measures of uncertainty and that of the financial stress, over and above the real returns itself, we now turn our attention to the causality-in-quantiles test.

As can be seen from Figures 2 to 20, the null hypothesis of no Granger causality is rejected (at 5 percent level of significance) around the median of the conditional distribution, in the following cases: Entitlement Program, EPU, Fiscal Policy, Government Spending, Health Care, News-based version of the EPU, and Taxes. The fact that these seven predictors predict the real returns around the median, implies that these variables carry important information, when the real returns of the US DJSI is performing in its normal mode.

In the same set of Figures, we also report the causality test over two sub-samples: a prefinancial crisis period (2002:02-2006:12) and a post-financial crisis period (2007:012014:12). As can be seen from the results of the sub-samples, there is no evidence of causality from any of the predictors for the pre-crisis period. However, for the post-crisis period, besides, the seven variables which had predictability for the full-sample, two more predictors are added, namely, CPI Disagreement and National Security. Moreover, the predictability tends to hold over a bigger part of the distribution covering the median to relatively upper end of the distribution. Note that, some marginal evidence of predictability from Sovereign Debt is also observed at the lower and upper-ends of the conditional distribution of the real returns. Clearly then, the evidence of causality for the full-sample

\footnotetext{
10 Though our objective is to analyse the causality-in-quantiles running from uncertainty and financial stressbased predictors to the real US DJSI stock returns, for the sake of completeness and comparability, we also conducted the standard linear Granger causality test based on a VAR(1). We observed that, barring the case of uncertainty arising from Financial Regulation, there is no evidence of predictability originating from the eighteen other predictors. The details of these results are available upon request from the authors.
} 
comes primarily from post-crisis period. Overall, our results highlight the importance of accounting for nonlinearity when testing for the role of uncertainty (as KCFSI has no role) in predicting real returns on the US DJSI, and also these predictors tend to have important causal information, especially when the market is performing in a normal fashion. Monetary policy uncertainty is associated with the conditions prevailing in the money market. In particular, as Apergis (2015) pointed out although central bank is committed to preserving liquidity the existence of a zero lower bound restriction and the adoption of unconventional monetary policy tools seem to have precipitated monetary shocks uncertainty.

On the other hand, fiscal policy conveys information for stock returns since during crisis periods it is expected that fiscal expansions might pave the way away from the crisis. However, the ability of government to implement expansionary policy is undermined by the levels of public debt which justifies in turn the predictive ability of the public debt related indicator. Finally, the role of inflation uncertainty in conventional stock investments has been thoroughly analyzed (see inter alia Campbell, 1987) and it appears to carry predictive power for sustainable stock investments.

\section{[INSERT FIGURES 2 TO 20 HERE]}

\section{Conclusions and policy implications}

Sustainable investments have undoubtedly been in the spotlight of global investing over the last decades as reflected in the growth of total assets under management. Thus researchers, investors and academics are growingly concerned whether sustainable returns are predictable to a certain extent. To this end, in the context of the present study we attempt to fill in this gap by examining the causality between the US Dow Jones Sustainability Index and a wide set of US policy uncertainty indicators along with a financial distress index namely the Kansas City Financial Stress Index (KCFSI). The analyzed period extends from January 2002 to December 2014 incorporating the effects of the recent global financial crisis. In particular, our sample is subdivided into two non-overlapping samples before and after the global financial crisis in order to isolate any crisis-induced behavior of the hypothesized relations. 
In general, the empirical results highlight a rather non-linear behavior of the returns distribution. Moreover, based on the findings US DJSI real returns are well predicted by seven uncertainty indicators namely Entitlement Program, EPU, Fiscal Policy, Government Spending, Health Care, News-based version of the EPU, and Taxes. In particular, only for the post-crisis period predictability of sustainable returns is evident. It is worth mentioning that besides the seven variables, which had predictability for the full-sample, two more predictors are added, namely, CPI Disagreement and National Security. Moreover, the predictability tends to hold over a bigger part of the distribution covering the median to relatively upper end of the distribution.

It has long been recognized that macroeconomic policy uncertainty exerts a negative effect on stock market performance. For example, Antonakakis et al. (2013) documented a negative correlation between stock market returns and policy uncertainty while Pastor and Veronesi (2013) pointed out that uncertainty about political decisions affects pricing in the stock markets. In particular, they claimed that political news contributes substantially to equity market risk premium. Therefore, we believe that our analysis on the interaction between sustainable investments and policy uncertainty might entail policy implications for all market participants, namely, market authorities and for portfolio managers and investors that choose to invest in sustainable investments. Stated differently, our study carries significant implications for investing and asset pricing purposes in the context of sustainable investments. We provide evidence that policy related risks might be priced in sustainable investments especially after the global financial crisis as it is the case with conventional investments (Apergis, 2015). Moreover, if sustainable investments' returns are related to certain policy related variables this information might be relevant for market timing strategies adopted by investors.

\section{Acknowledgements}

We would like to thank the editor (Mark Taylor) and two anonymous reviewers for their very insightful comments on a previous version of this paper. The usual disclaimer applies. 


\begin{tabular}{llllll}
\hline & \multicolumn{5}{l}{ Dimension } \\
\cline { 2 - 6 } & 2 & 3 & 4 & 5 & 6 \\
\hline Real US DJSI Returns & 0.02 & 0.00 & 0.00 & 0.00 & 0.00 \\
\hline CPI Disagreement & 0.03 & 0.00 & 0.00 & 0.00 & 0.00 \\
\hline Debt Ceiling & 0.01 & 0.00 & 0.00 & 0.00 & 0.00 \\
\hline Entitlement Program & 0.00 & 0.00 & 0.00 & 0.00 & 0.00 \\
\hline EPU & 0.00 & 0.00 & 0.00 & 0.00 & 0.00 \\
\hline Federal-State-Local & 0.01 & 0.00 & 0.00 & 0.00 & 0.00 \\
Disagreement & & & & 0.00 & \\
\hline Financial Regulation & 0.12 & 0.00 & 0.00 & 0.00 & 0.00 \\
\hline Fiscal Policy & 0.01 & 0.00 & 0.00 & 0.00 & 0.00 \\
\hline Government Shut-Down & 0.00 & 0.00 & 0.00 & 0.00 & 0.00 \\
\hline Government Spending & 0.01 & 0.00 & 0.00 & 0.00 & 0.00 \\
\hline Health Care & 0.00 & 0.00 & 0.00 & 0.00 & 0.00 \\
\hline National Security & 0.02 & 0.00 & 0.00 & 0.00 & 0.00 \\
\hline Monetary Policy & 0.18 & 0.00 & 0.00 & 0.00 & 0.00 \\
\hline News Component of EPU & 0.04 & 0.00 & 0.00 & 0.00 & 0.00 \\
\hline Regulation & 0.03 & 0.00 & 0.00 & 0.00 & 0.00 \\
\hline Taxes & 0.01 & 0.00 & 0.00 & 0.00 & 0.00 \\
\hline Sovereign Debt & 0.02 & 0.00 & 0.00 & 0.00 & 0.00 \\
\hline Tax Expiration & 0.02 & 0.00 & 0.00 & 0.00 & 0.00 \\
\hline Trade Policy & 0.00 & 0.00 & 0.00 & 0.00 \\
\hline KCFSI & 0.00 & 0.00 \\
\hline Nonyyyyyyyy & & & & 0.00 \\
\hline
\end{tabular}

Note: Values in cells represent $p$-value of the BDS test statistics. 

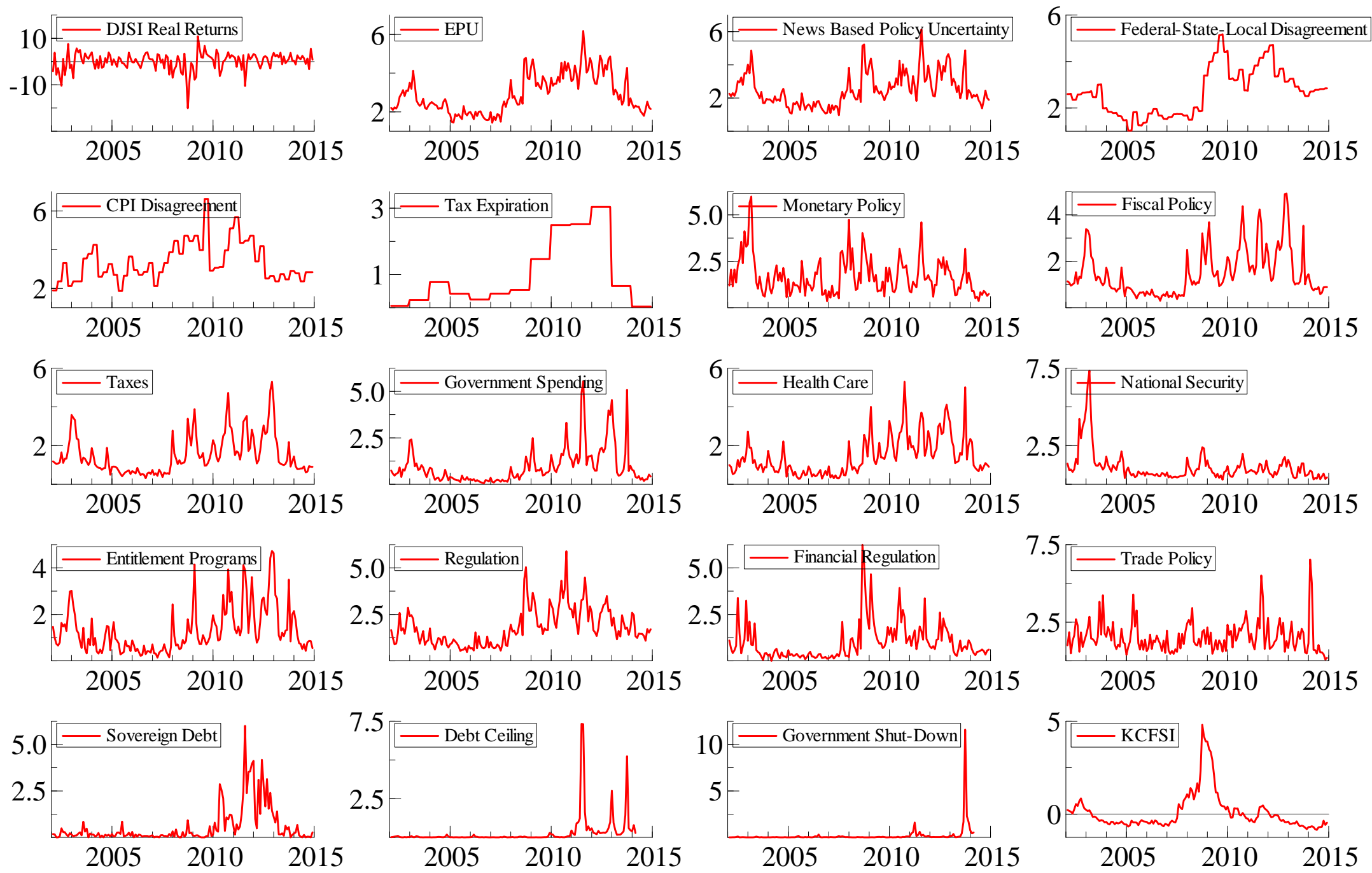

Figure 1: Plots of underlying series (in natural logarithms)

Source: Authors’ calculations based on http://www.policyuncertainty.com/categorical_terms.html. 


\section{Causality-in-Quantiles}

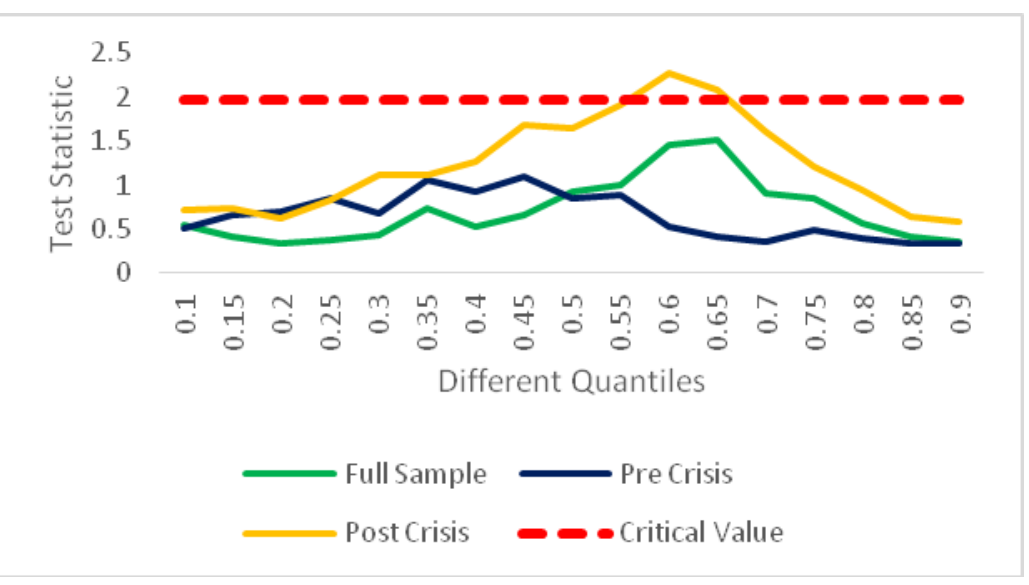

Figure 2: Causality-in-Quantiles: CPI Disagreement

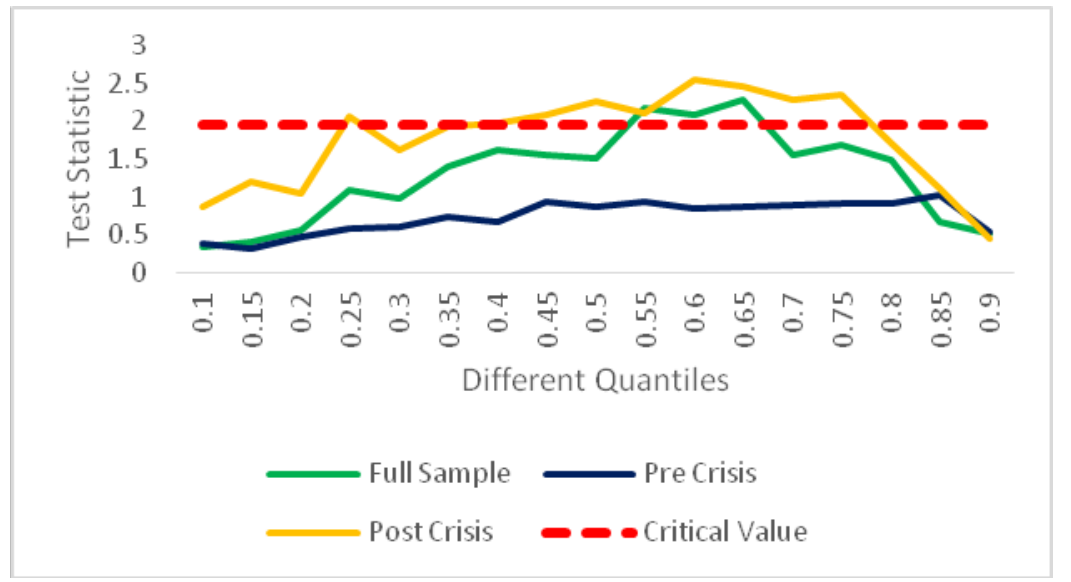

Figure 4: Causality-in-Quantiles: Entitlement Program

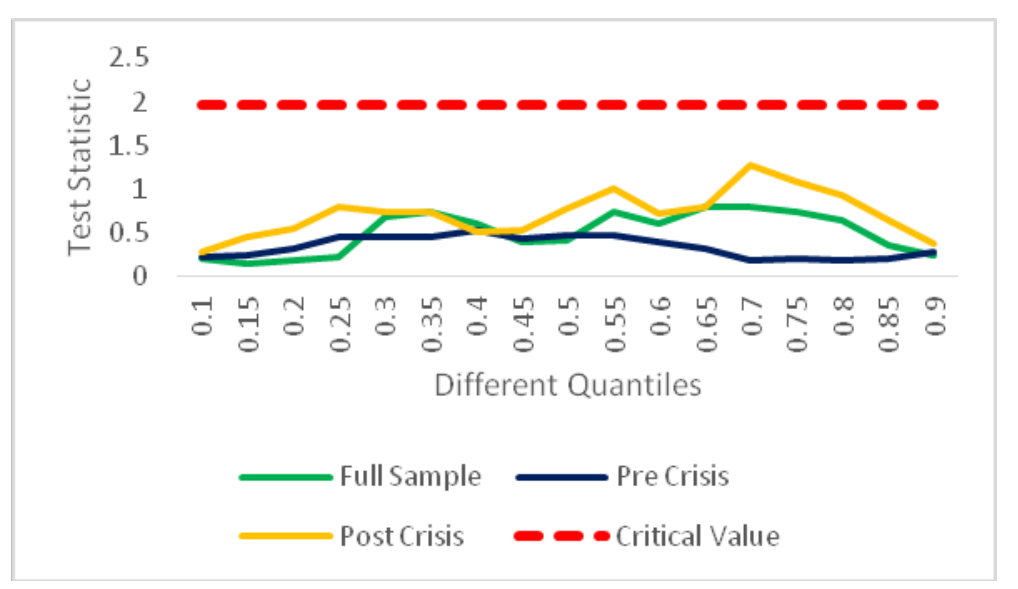

Figure 3: Causality-in-Quantiles: Debt Ceiling

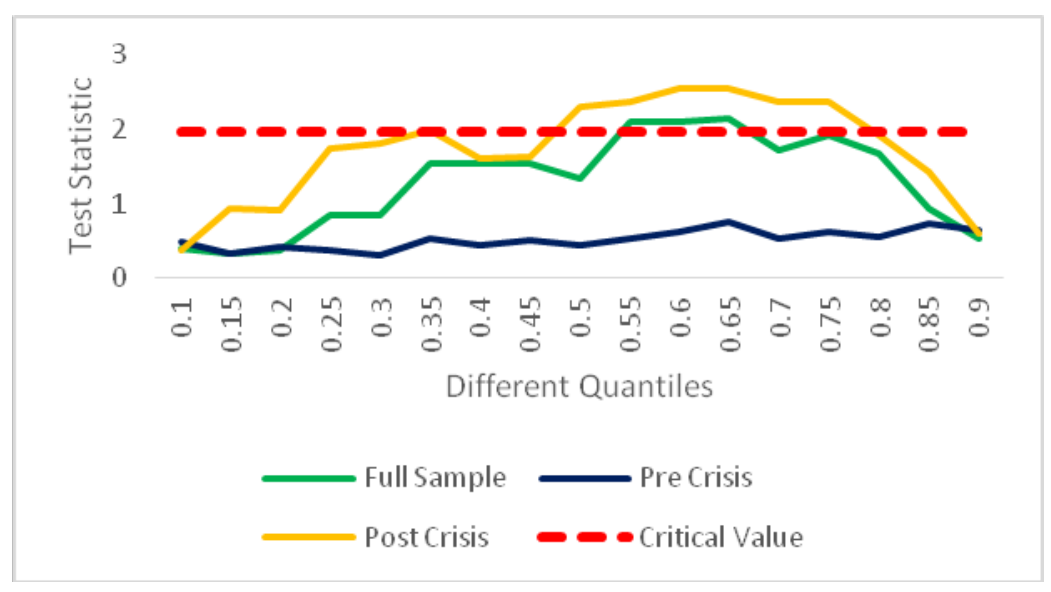

Figure 5: Causality-in-Quantiles: EPU 


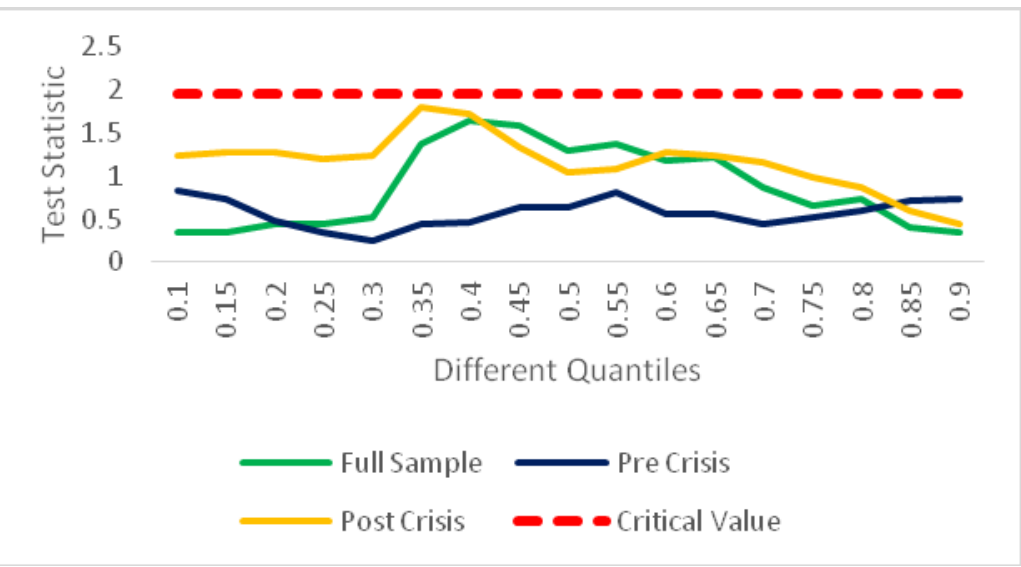

Figure 6: Causality-in-Quantiles: Federal-State-Local Disagreement

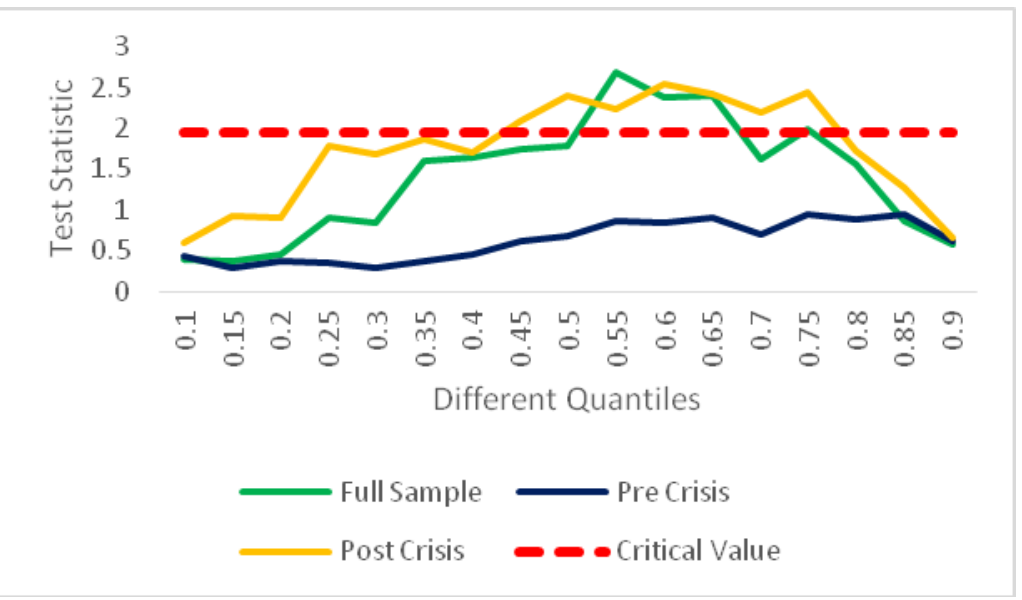

Figure 8: Causality-in-Quantiles: Fiscal Policy

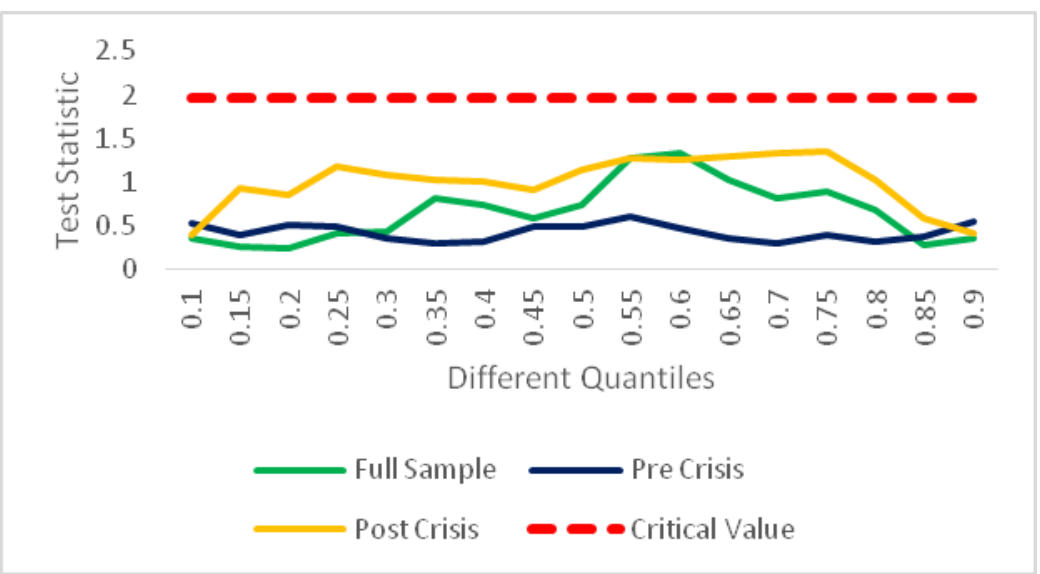

Figure 7: Causality-in-Quantiles: Financial Regulation

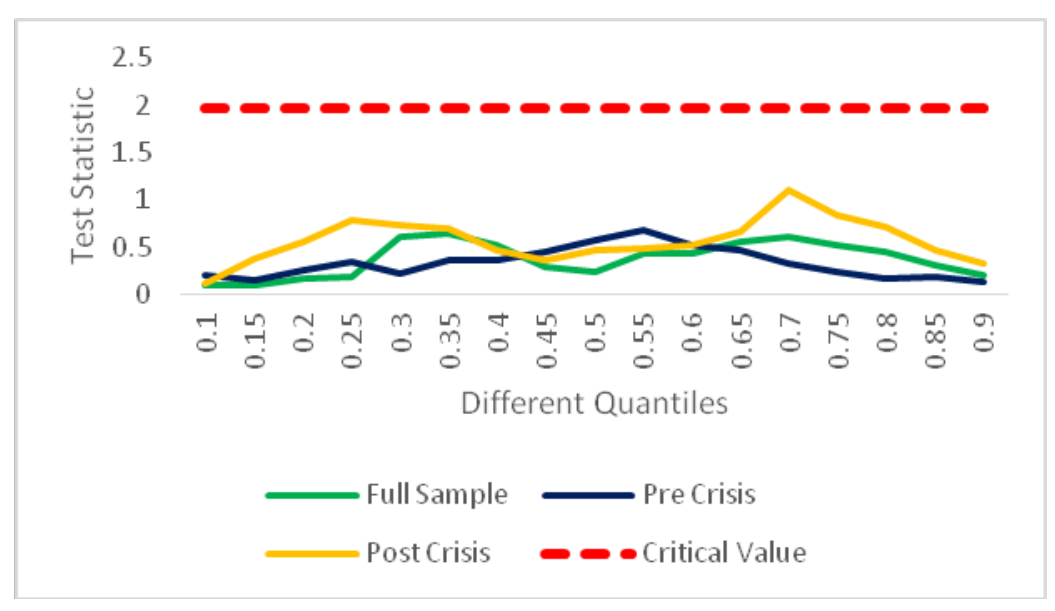

Figure 9: Causality-in-Quantiles: Government Shut-Down 


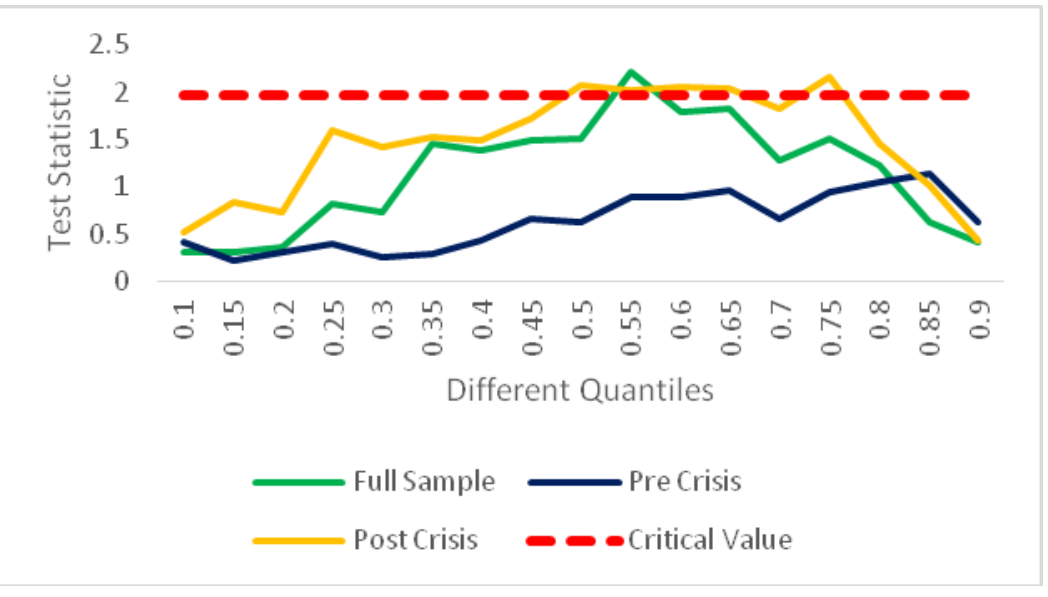

Figure 10: Causality-in-Quantiles: Government Spending

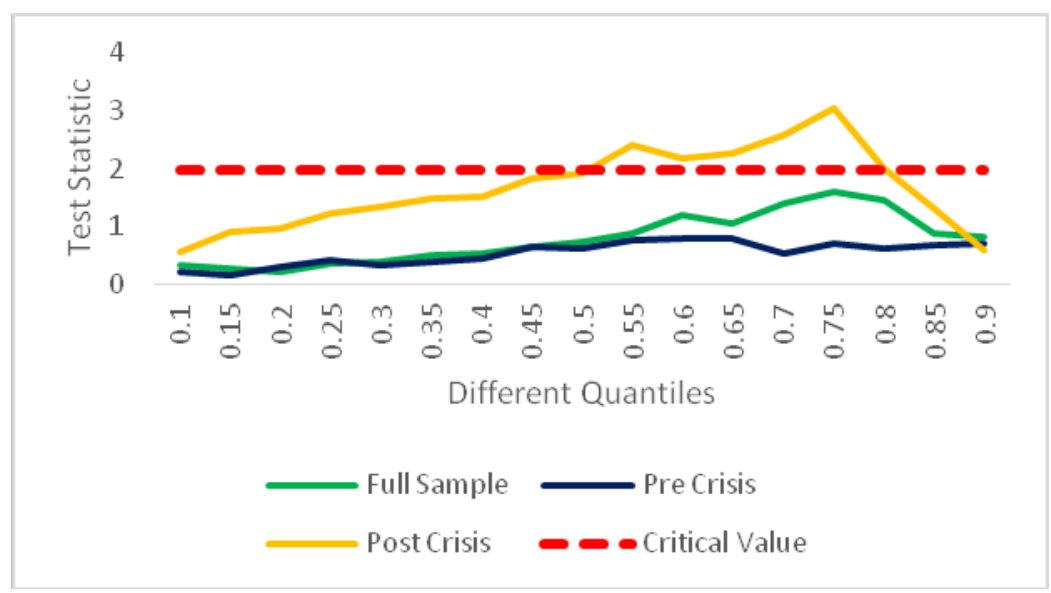

Figure 12: Causality-in-Quantiles: National Security

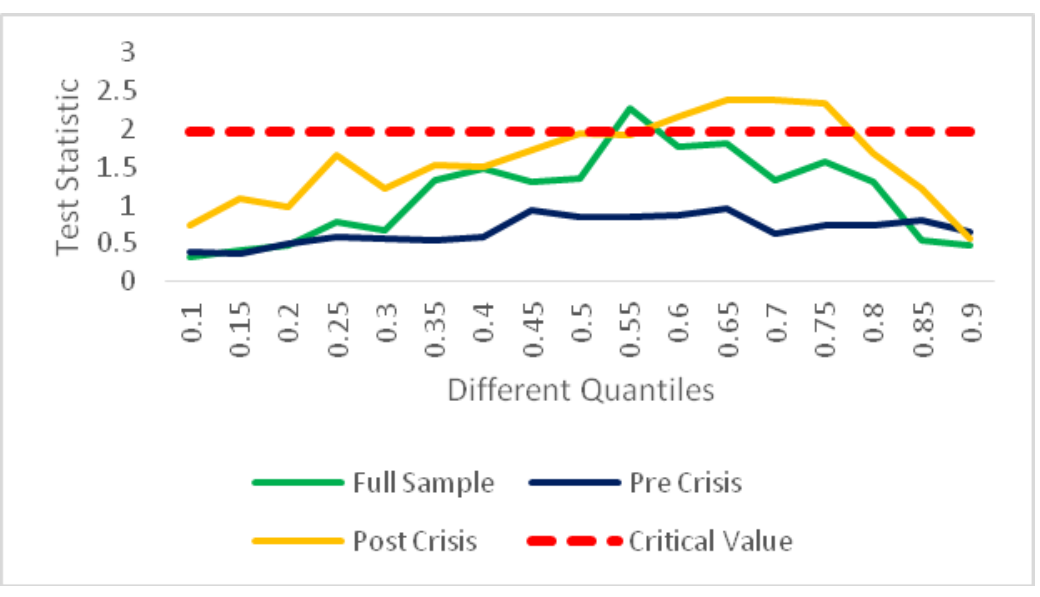

Figure 11: Causality-in-Quantiles: Health Care

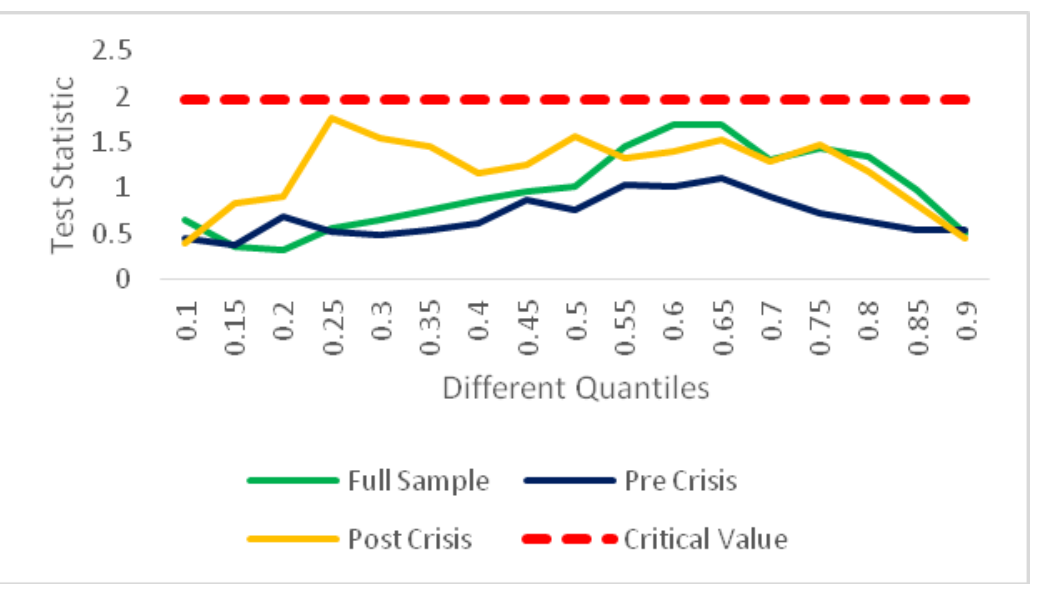

Figure 13: Causality-in-Quantiles: Monetary Policy 


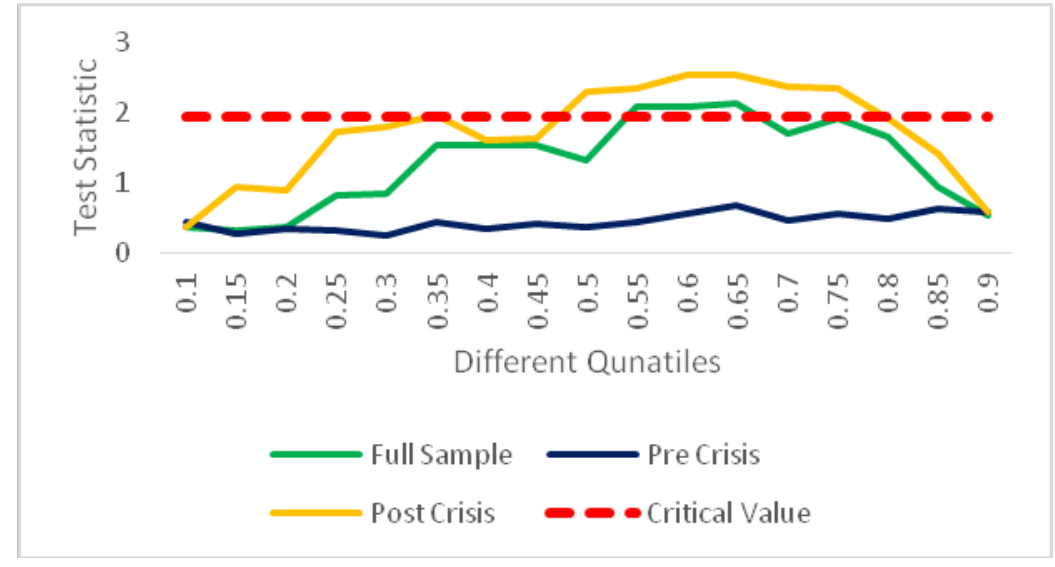

Figure 14: Causality-in-Quantiles: News-Based EPU

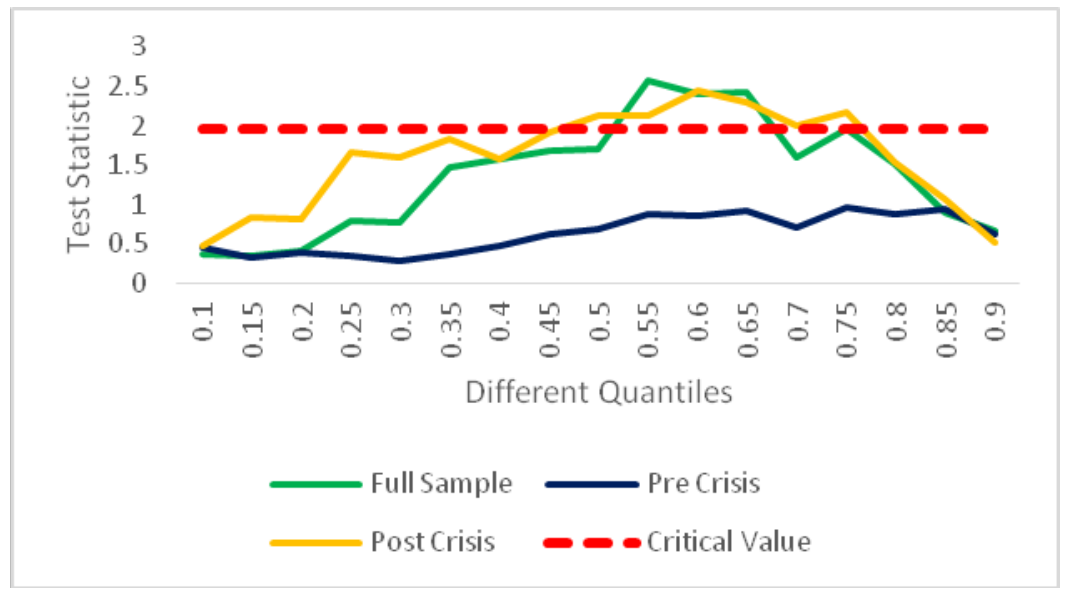

Figure 16: Causality-in-Quantiles: Taxes

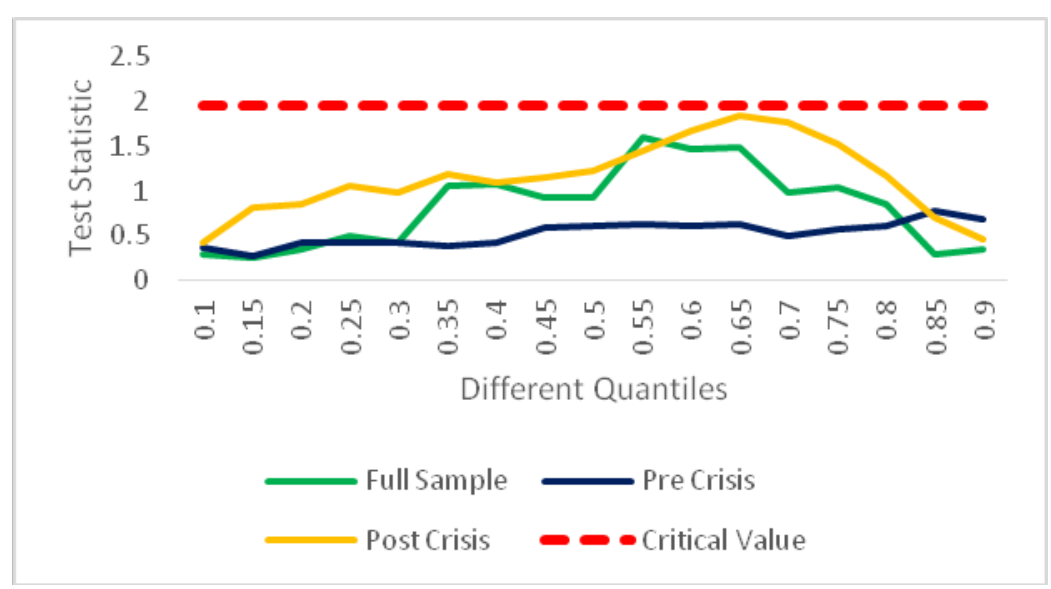

Figure 15: Causality-in-Quantiles: Regulation

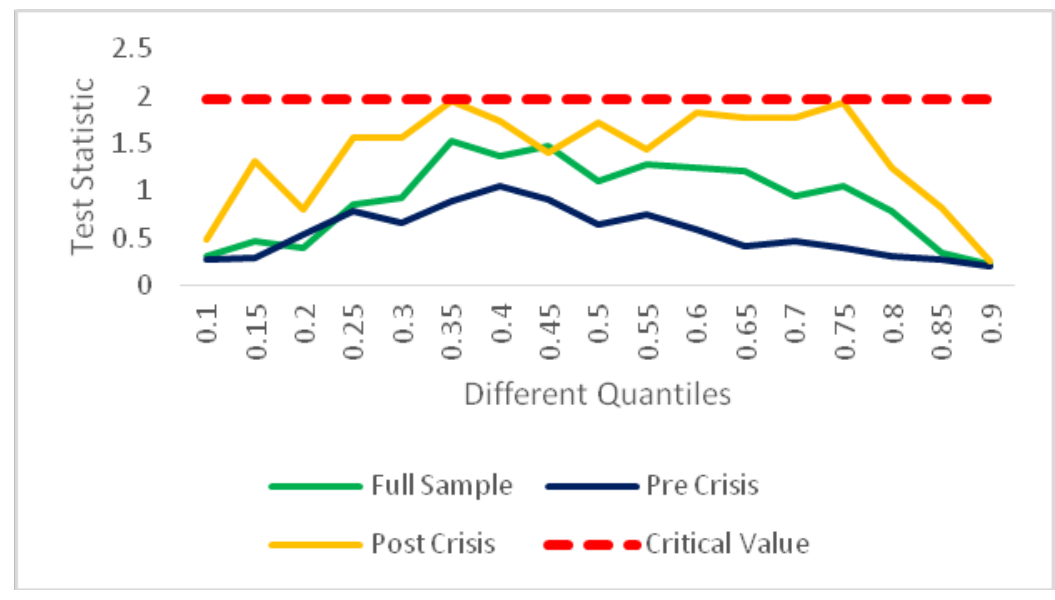

Figure 17: Causality-in-Quantiles: Sovereign Debt 


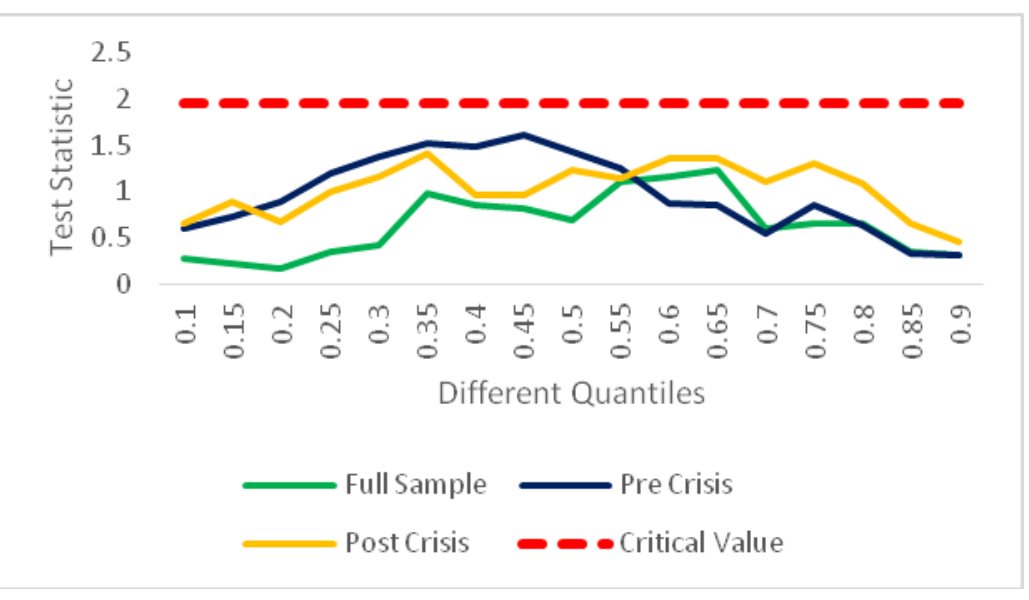

Figure 18: Causality-in-Quantiles: Tax Expiration

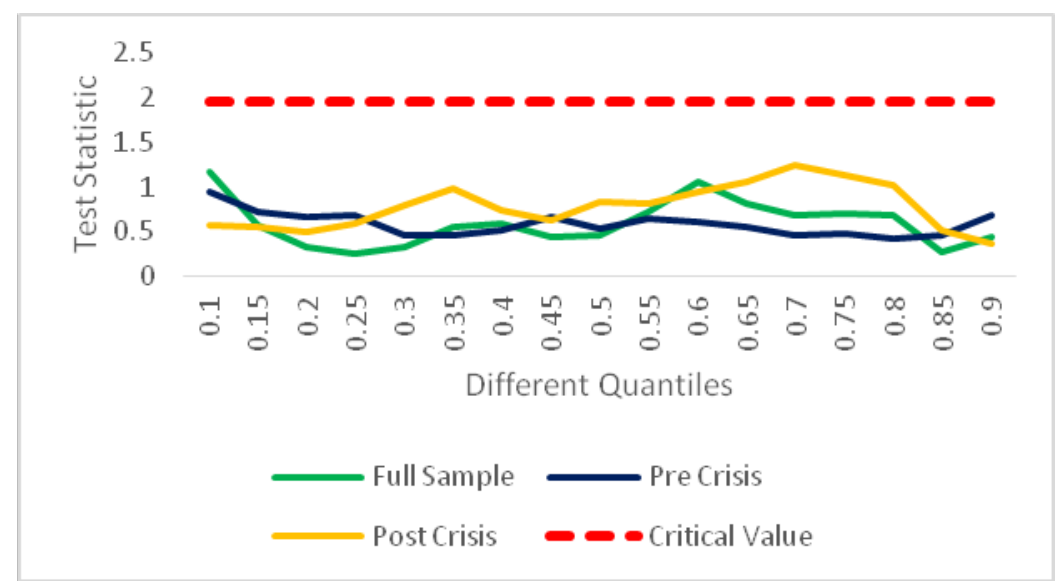

Figure 20: Causality-in-Quantiles: KCFSI

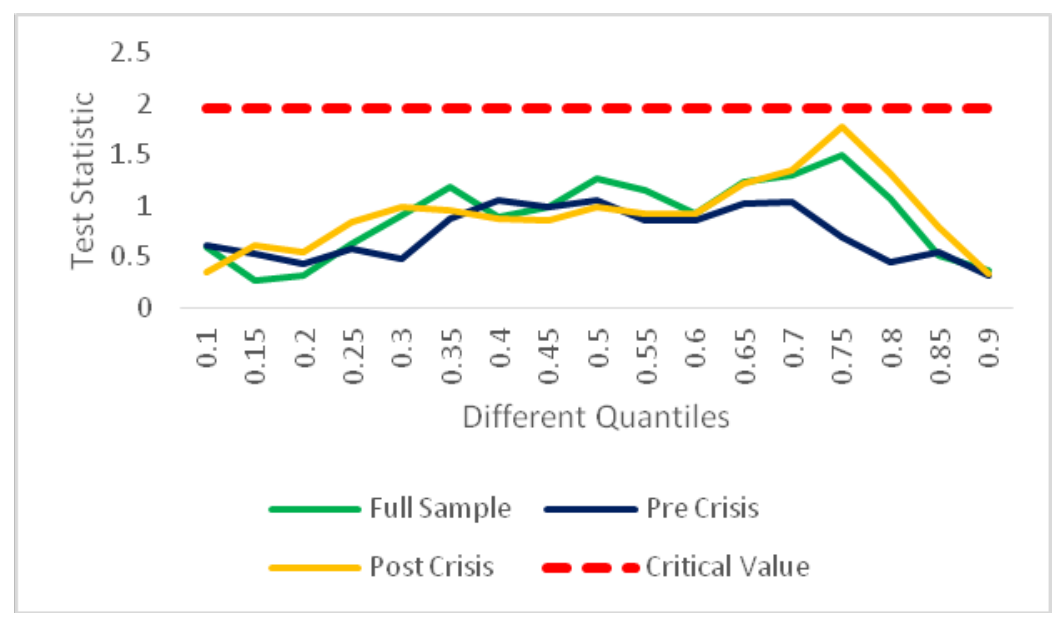

Figure 19: Causality-in-Quantiles: Trade Policy 


\section{References}

Antonakakis, N. Chatziantoniou, I, Filis, G, 2013. "Dynamic co-movements of stock market returns, implied volatility and policy uncertainty," Economics Letters 120, pp. 87-92.

Apergis, N., 2015. Policy risks, technological risks and stock returns: New evidence from the US stock market. Economic Modelling 52, 359-365.

Baker, S., Bloom, N., Davis, S., 2013. Measuring Economic Policy Uncertainty. Chicago Booth Research Paper No. 13-02.

Basu, S. 1997. 'The Investment Performance of Common Stocks in Relation to their PriceEarningsRatios: A Test of the Efficient Market Hypothesis', Journal of Finance 32, pp.663682.

Bomfim, A.N., 2003. Pre-announcement effects, news effects, and volatility: Monetary policy and the stock market, Journal of Banking \& Finance 27(1), 133-151.

Breen, W., Glosten, L.R., Jagannathan, R., 1990. Predictable variations in stock index returns. Journal of Finance 44 1177-1189.

Brock, W., Dechert, D., Scheinkman, J., LeBaron, B., 1996. A test for independence based on the correlation dimension. Econometric Reviews 15 197-235.

Campbell, J.Y., 1987. Stock returns and the term structure. Journal of Financial Economics 373399.

Campbell, J.Y. Hentschel, L., 1992. No news is good news, Journal of Financial Economics 31(3), 281-318.

Chava, S., Gallmeyer, M. Park, H. 2015.Credit conditions and stock return predictability. Journal of Monetary Economics 74, 117-132.

Chen, S.-S., 2007. Does Monetary Policy Have Asymmetric Effects on Stock Returns? Journal of Money, Credit and Banking 39(2/3), 667-688.

Chu, X., 2015. Modelling impact of monetary policy on stock market liquidity: A dynamic copula approach. Applied Economics Letters 22(10), 820-824.

Clare, A.D., Thomas, S.H., Wickens, M.R., 1994. Is the gilt equity yield ratio useful for predicting UK stock returns? Economic Journal 104, 303-315.

Day, R. H., Huang, W., 1990. Bulls, bears and market sheep, Journal of Economic Behavior \& Organization 14(3), 299-329.

Epps, T. W., 1975. Security Price Changes and Transaction Volumes: Theory and Evidence. The American Economic Review 65(4), 586-597. 
Fama, E.F. and French, K.R. 1992. 'The Cross-Section of Expected Stock Returns', Journal of Finance 47, 427-465.

Fama, E.F. and French, K.R. 1993. "Common risk factors in the returns on stocks and bonds”, Journal of Financial Economics 33, 3-56.

Fama, E.F., French, K.R., 1998. Value versus growth: The international Evidence. Journal of Finance 53, 1975-1999.

Ghoul, W., Karam, P., 2007. MRI and SRI mutual funds: A comparison of Christian, Islamic (morally responsible investing), and socially responsible investing (SRI) mutual funds. Journal of Investing 16(2), 96-102.

Guo, H., 2006. On the out of sample predictability of stock market returns. Journal of Business 79 (2), 645-670.

Jeong, K., Härdle, W. K., Song, S., 2012. A consistent nonparametric test for causality in quantile. Econometric Theory 28(04), 861-887.

Kanga, W., Ratti, A.R.2013. Oil Shocks, Policy Uncertainty and Stock Market Return. Journal of International Financial Markets, Institutions and Money 26, 305-318.

Keim, D.B. and Stambaugh, R.F. 1986. Predicting Returns in the Stock and Bond Markets, Journal of Financial Economics 17, 357-390.

Koutmos, G., Booth, G.G. 1995. Asymmetric volatility transmission in international stock markets, Journal of International Money and Finance 14(6), 747-762.

Lean, H.H., Nguyen, D. K. 2014. Policy uncertainty and performance characteristics of sustainable investments across regions around the global financial crisis. Applied Financial Economics 24, 1367-1373.

Lewellen, J., 2004. Predicting returns with financial ratios. Journal of Financial Economics 74 (2), 209-235.

Li, J., 2015. The asymmetric effects of investor sentiment and monetary policy on stock prices. Applied Economics 47(24), 2514-2522.

Moskowitz, M.R., 1972. Choosing socially responsible stocks. Business \& Society Review 1, $71-75$.

Narayan, P.K., Narayan, S., Thuraisamy, K.S. 2014. Can institutions and macroeconomic factors predict stock returns in emerging markets? Emerging Markets Review 19, 77-95.

Pastor, L., Veronesi, P., 2012. Uncertainty about Government Policy and Stock Prices. Journal of Finance 67, 1219-1264.

Pástor, L., Veronesi, P., 2013. Political uncertainty and risk premia. Journal of Financial Economics 110, 520-545. 
Pesaran, M.H., Timmermann, A., 1994. Forecasting stock returns. An examination of stock market trading in the presence of transaction costs. Journal of Forecasting 13, 330-365.

Pesaran, M.H., Timmermann, A., 1995. The robustness and economic significance of predictability of stock returns. Journal of Finance 50, 1201-1228.

Pesaran, M.H., Timmermann, A., 2000. Recursive modelling approach to predicting UK stock returns. Economic Journal 110, 159-191.

Renneboog, L., Ter Horst, J., Zhang, C., 2008. Socially responsible investments: Institutional aspects, performance, and investor behavior. Journal of Banking and Finance 32(9), 1723-1742.

Veronesi, P., 1999. Stock Market Overreactions to Bad News in Good Times: A Rational Expectations Equilibrium Model. The Review of Financial Studies 12(5), 975-1007. 